\section{(2) OPEN ACCESS}

\title{
Diagnosis of osteoporosis in statin-treated patients is dose-dependent
}

\author{
Michael Leutner, ${ }^{1}$ Caspar Matzhold, ${ }^{2,3}$ Luise Bellach, ${ }^{1}$ Carola Deischinger, ${ }^{1}$ \\ Jürgen Harreiter, ${ }^{1}$ Stefan Thurner, ${ }^{2,3,4,5}$ Peter Klimek, ${ }^{2,3}$ Alexandra Kautzky-Willer (D) ${ }^{1}$
}

\begin{abstract}
Handling editor Francis Berenbaum

- Additional material is published online only. To view please visit the journal online (http://dx.doi.org/10.1136/ annrheumdis-2019-215714)
\end{abstract}

\section{${ }^{1}$ Department of Internal} Medicine III, Clinical Division of Endocrinology and Metabolism, Unit of Gender Medicine, Medical University of Vienna, Vienna, Austria

${ }^{2}$ Section for Science of Complex Systems, CeMSIIS, Medical University of Vienna, Vienna, Austria

${ }^{3}$ Complexity Science Hub Vienna, Vienna, Austria ${ }^{4}$ Santa Fe Institute, Santa Fe, New Mexico, USA ${ }^{5}$ IIASA, Laxenburg, Austria

\section{Correspondence to}

Professor Alexandra KautzkyWiller, Internal Medicine III, Division of Endocrinology and Metabolism, Medical University of Vienna, Vienna 1090, Austria; alexandra.kautzky-willer@ meduniwien.ac.at

Received 16 May 2019 Revised 27 August 2019 Accepted 12 September 2019 26 September 2019

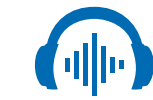

Listen to Podcast ard.bmj.com Published Online First

\section{ABSTRACT}

Objective Whether HMG-CoA-reductase inhibition, the main mechanism of statins, plays a role in the pathogenesis of osteoporosis, is not entirely known so far. Consequently, this study was set out to investigate the relationship of different kinds and dosages of statins with osteoporosis, hypothesising that the inhibition of the synthesis of cholesterol could influence sex-hormones and therefore the diagnosis of osteoporosis.

Methods Medical claims data of all Austrians from 2006 to 2007 was used to identify all patients treated with statins to compute their daily defined dose averages of six different types of statins. We applied multiple logistic regression to analyse the dose-dependent risks of being diagnosed with osteoporosis for each statin individually.

Results In the general study population, statin treatment was associated with an overrepresentation of diagnosed osteoporosis compared with controls (OR: $3.62,95 \% \mathrm{Cl} 3.55$ to $3.69, \mathrm{p}<0.01)$. There was a highly non-trivial dependence of statin dosage with the ORs of osteoporosis. Osteoporosis was underrepresented in low-dose statin treatment (0-10 mg per day), including lovastatin (OR: $0.39, \mathrm{Cl} 0.18$ to $0.84, \mathrm{p}<0.05$ ), pravastatin (OR: $0.68,95 \% \mathrm{Cl} 0.52$ to $0.89, \mathrm{p}<0.01$ ), simvastatin (OR: $0.70,95 \% \mathrm{Cl} 0.56$ to $0.86, \mathrm{p}<0.01$ ) and rosuvastatin (OR: $0.69,95 \% \mathrm{Cl} 0.55$ to $0.87, \mathrm{p}<0.01$ ). However, the exceeding of the $40 \mathrm{mg}$ threshold for simvastatin (OR: $1.64,95 \% \mathrm{Cl} 1.31$ to $2.07, \mathrm{p}<0.01$ ), and the exceeding of a $20 \mathrm{mg}$ threshold for atorvastatin (OR: $1.78,95 \% \mathrm{Cl} 1.41$ to $2.23, \mathrm{p}<0.01$ ) and for rosuvastatin (OR: $2.04,95 \% \mathrm{Cl} 1.31$ to $3.18, \mathrm{p}<0.01$ ) was related to an overrepresentation of osteoporosis. Conclusion Our results show that the diagnosis of osteoporosis in statin-treated patients is dosedependent. Thus, osteoporosis is underrepresented in low-dose and overrepresented in high-dose statin treatment, demonstrating the importance of future studies' taking dose-dependency into account when investigating the relationship between statins and osteoporosis.

\section{Check for updates}

(C) Author(s) (or their employer(s)) 2019. Re-use permitted under CC BY-NC. No commercial re-use. See rights and permissions. Published by BMJ.

To cite: Leutner $\mathrm{M}$, Matzhold C, Bellach L, et al. Ann Rheum Dis 2019;78:1706-1711.

\section{INTRODUCTION}

Osteoporosis is a chronic disease characterised by a reduced bone mineral density (BMD) induced by an imbalance in osteoblastic and osteoclastic bone formation and resorption. ${ }^{1}$ Due to the elevated fracture risk, osteoporosis can have detrimental effects on a patient's quality of life and is associated with a higher mortality and morbidity as well as being an economic burden. ${ }^{2}$ By now, numerous studies about osteoporosis and its treatment have

\section{Key messages}

What is already known about this subject?

- There is a relationship between statins and osteoporosis.

What does this study add?

- Osteoporosis is underrepresented in low-dose statin treatment.

- There is an overrepresentation of osteoporosis in high-dose statin treatment.

How might this impact on clinical practice or future developments?

- In clinical practice, high-risk patients for osteoporosis under high-dose statin treatment should be monitored more frequently.

been conducted-many of which revolve around the question whether statins affect bone metabolism. ${ }^{3-10}$ Statins play a crucial role in the management of hypercholesterolemia, which makes them a commonly used drug. ${ }^{11}$ Actual guidelines for the treatment of hypercholesterolemia in highrisk patients suffering from cardiovascular disease (CVD) or diabetes have been issued, recommending cholesterol levels to be as low as possible. ${ }^{12}$ Therefore, due to the sheer number of patients under statin therapy, research on the connection between statin usage and osteoporosis risk is of great importance. In particular, the underlying pathophysiological mechanisms of a possible osteoprotective effect of statins have yet to be fully established. ${ }^{3} 1314$ Although many observational studies report positive effects of statin use on BMD and/or fracture risk, existing data do not sufficiently support the use of statins as osteoporosis prophylaxis. This is mainly due to the heterogeneity of the data concerning the effect of statin therapy on bone formation markers, BMD in females and overall BMD and fracture risk, ${ }^{3}$ as well as the lack of data regarding the relationship between different kinds and dosages of statins and diagnosis of osteoporosis. Another topic causing controversy is the question whether statins affect sex hormone levels such as testosterone or oestrogen. ${ }^{15-17}$ Statins act by inhibiting the endogenous synthesis of cholesterol, the main substrate for the synthesis of sex hormones, and thus we cannot disregard the possibility of a negative effect of statins on bone health, especially in higher dosages. However, data on the dosage-dependency of statins in the diagnosis of 
osteoporosis are sparse. Consequently, the present study seeks to investigate the relationship between different kinds and dosages of statins and osteoporosis and to shed light on the controversy regarding the relationship between statin treatment and the diagnosis of osteoporosis in a nationwide population-based study.

\section{STUDY DESIGN AND METHODS}

We conducted a cross-sectional retrospective analysis of the entire Austrian population using a consolidated administrative research data base. ${ }^{18}$

\section{Patient population}

Our data include all Austrians with health claims (roughly 97\% of the population) for which data on all main and side diagnoses from hospital stays and all prescriptions of drugs with costs that exceed a prescription charge of EUR 4.70 is available. We included patients with uniquely identifiable age and sex who were alive during the entire observation period from January 2006 to December 2007 ( $n=7945$ 775). Patients born in these years or with age $>90$ years were excluded to gain a more homogenous group of patients. The obtained cohort consisted of 7897449 patients (male $=3702$ 572; female $=4194$ 877). Information on prescriptions was available in the Anatomical Therapeutic Chemical (ATC) Classification System codes; to identify patients being diagnosed with osteoporosis, main and side diagnoses from hospital stays were extracted as International Classification of Diseases, 10th revision (ICD10) codes. Patients with a main or side diagnosis from the range M80-M82 (including M80: 'Osteoporosis with current pathological fracture', M81: 'Osteoporosis without current pathological fracture' and M82: 'Osteoporosis in diseases classified elsewhere' (defined as osteoporosis in multiple myelomatosis or endocrine disorders) were classified as osteoporosis patients. We additionally conducted a sensitivity analysis to control for occurrences of rheumatoid arthritis (ICD10 code M06), ischaemic heart diseases (any code from the range I20-I25), diseases or arteries including arterioles and capillaries (I70-I79), stroke (I63, I64), diabetes (E10, E11), chronic renal insufficiency (N17-N19), nicotine dependency (F17), overweight and obesity (E65-E68), chronic obstructive pulmonary disease (J44), asthma (J45) and Crohn's disease (K50).

\section{Identifying patients with statin treatment}

We identified all patients who had at least one prescription of any of the seven statins available on the market during the observation period: Simvastatin (ATC-code: C10AA01), Lovastatin (ATC-code: C10AA02), Pravastatin (ATC-code: C10AA03), Fluvastatin (ATC-code: C10AA04), Atorvastatin (ATC-code: C10AA05), Cerivastatin (ATC-code: A10AA06) and Rosuvastatin (ATC-code: C10AA07). For these patients, we additionally controlled for possible effects of other prescribed drugs including 49 different kinds of insulin-sparing or providing medication (all ATC-codes starting with A10) and 3 fibrates (ATC-code: C10AB02, C10B05, C10A×09).

For each medication, we tested if the patient was a regular drug user or not. Only if a patient had a minimum of four different prescription entries for a given drug, we identified him/ her as a valid drug user. As most health claims are filed on a quarterly basis, four different prescription entries are equivalent to a treatment regularly applied over 1 year. Medications with less than 35 valid patients were excluded. The control group was made up of all patients not treated with statins.

\section{Average daily doses}

The average daily dose of a given drug for each patient was calculated as the amount of the drug (converted from defined daily dose to $\mathrm{mg}^{1}$ ) divided by the number of treatment days that the patient did not spend in a hospital. Patients were then grouped according to their average daily dose for each statin in groups of $>0-10 \mathrm{mg},>10-20 \mathrm{mg},>20-40 \mathrm{mg},>40-60 \mathrm{mg}$ and $>60-80 \mathrm{mg}$.

\section{Patient and public involvement}

Patients were not involved in the study design. Details of the ethical approval are provided in the online supplementary material.

\section{Statistical analyses}

We computed age-specific and sex-specific ORs between statin use and being diagnosed with osteoporosis. Multiple logistic regression was used to investigate this association while controlling for age, sex, dosage and prescription of other medications (drugs used in diabetes and fibrates). Next to age and sex, the independent variables in the regression included the dosage category for each type of statin or other medication as a categorical variable. Patients were assigned a categorical variable for each statin according to their average daily dose in milligrams. We controlled for other medications (20 glucose lowering drugs, including metformin; 3 fibrates) by introducing binary dummy variables for whether the patient fulfilled all criteria to be considered a valid drug user or not (see above). Goodness of fit of the regression models was evaluated by the adjusted R-squared statistic; the variance inflation factor (VIF) was used to test for multicollinearity.

\section{RESULTS}

\section{Baseline characteristics}

We identified 353502 statin-treated patients (175506 males, 177996 females) out of which 11701 patients (1765 males, 9936 females) were diagnosed with osteoporosis (for a detailed description of the osteoporotic population, see also online supplementary tables S1 and S2). The control group (no statin exposure) consisted of 7543947 patients (3527066 males, 4016881 females), including 68699 patients (10410 males, 58289 females) diagnosed with osteoporosis. Table 1 presents the results of a sex-matched and age-matched cohort analysis of statin users in comparison to non-statin users and shows that statin users presented more often with a diagnosis of CVD, renal failure, nicotine dependency, overweight and obesity and were treated more often with antidiabetics.

\section{Sex-specific comparison of the diagnosis of osteoporosis}

Within the whole study population, our results show that women are at a higher risk of being diagnosed with osteoporosis when compared with men (OR: 5.08, 95\% CI 4.98 to 5.18, p<0.01; see also online supplementary table S3).

\section{Comparison of the diagnosis of osteoporosis between patients with and without statin treatment}

In the present analysis, the diagnosis of osteoporosis was more prevalent in patients of any age treated with statins when compared with control subjects without statin treatment (OR: $3.62,95 \%$ CI 3.55 to $3.69, \mathrm{p}<0.01)$. In a sex-specific analysis, the diagnosis of osteoporosis was overrepresented in both statintreated females (OR(f): $3.90,95 \%$ CI 3.81 to $3.98, \mathrm{p}<0.01)$ and males $(\mathrm{OR}(\mathrm{m}): 3.35,95 \% \mathrm{CI} 3.18$ to $3.52, \mathrm{p}<0.01)$. Therefore, 


\begin{tabular}{|c|c|c|c|c|}
\hline & \multicolumn{2}{|l|}{ Statin } & \multicolumn{2}{|c|}{ Matched control } \\
\hline & Male & Female & Male & Female \\
\hline $\mathrm{N}$ & 175506 & 177996 & 526518 & 533988 \\
\hline Age $($ mean $\pm S D)$ & $65.02 \pm 10.89$ & $69.02 \pm 10.46$ & $65.02 \pm 10.89$ & $69.02 \pm 10.46$ \\
\hline Osteoporosis (M80-M82) & $\begin{array}{l}1765 \\
(1.01 \%)\end{array}$ & $\begin{array}{l}9936 \\
(5.58 \%)\end{array}$ & $\begin{array}{l}5.264 \\
(1.00 \%)\end{array}$ & $\begin{array}{l}26.903 \\
(5.04 \%)^{* *}\end{array}$ \\
\hline Insulin & $\begin{array}{l}11690 \\
(6.66 \%)\end{array}$ & $\begin{array}{l}12332 \\
(6.93 \%)\end{array}$ & $\begin{array}{l}8603^{* *} \\
(1.63 \%)\end{array}$ & $\begin{array}{l}8617^{* *} \\
(1.61 \%)\end{array}$ \\
\hline Oral antidiabetics & $\begin{array}{l}34511 \\
(19.66 \%)\end{array}$ & $\begin{array}{l}32514 \\
(18.27 \%)\end{array}$ & $\begin{array}{l}32569^{\star *} \\
(6.19 \%)\end{array}$ & $\begin{array}{l}31237^{* *} \\
(5.85 \%)\end{array}$ \\
\hline Fibrates & $\begin{array}{l}3667 \\
(2.09 \%)\end{array}$ & $\begin{array}{l}1993 \\
(1.12 \%)\end{array}$ & $\begin{array}{l}6470^{* *} \\
(1.23 \%)\end{array}$ & $\begin{array}{l}8131^{* *} \\
(1.52 \%)\end{array}$ \\
\hline Arthritis (M06) & $\begin{array}{l}359 \\
(0.20 \%)\end{array}$ & $\begin{array}{l}991 \\
(0.56 \%)\end{array}$ & $\begin{array}{l}988 \\
(0.19 \%)\end{array}$ & $\begin{array}{l}2.703^{*} \\
(0.51 \%)\end{array}$ \\
\hline CVD (120-125) & $\begin{array}{l}36970 \\
(21.06 \%)\end{array}$ & $\begin{array}{l}23998 \\
(13.48 \%)\end{array}$ & $\begin{array}{l}33971 \\
(6.45 \%)\end{array}$ & $\begin{array}{l}27814^{* *} \\
(5.21 \%)\end{array}$ \\
\hline Stroke $(163,164)$ & $\begin{array}{l}5164 \\
(2.94 \%)\end{array}$ & $\begin{array}{l}4429 \\
(2.49 \%)\end{array}$ & $\begin{array}{l}8250^{* *} \\
(1.57 \%)\end{array}$ & $\begin{array}{l}7875^{* *} \\
(1.47 \%)\end{array}$ \\
\hline Diseases of arteries (170-179) & $\begin{array}{l}12513 \\
(7.13 \%)\end{array}$ & $\begin{array}{l}9058 \\
(5.09 \%)\end{array}$ & $\begin{array}{l}17621^{* *} \\
(3.35 \%)\end{array}$ & $\begin{array}{l}13605^{* *} \\
(2.55 \%)\end{array}$ \\
\hline Renal failure (N17-N19) & $\begin{array}{l}8148 \\
(4.64 \%)\end{array}$ & $\begin{array}{l}6684 \\
(3.76 \%)\end{array}$ & $\begin{array}{l}15774^{* *} \\
(3.00 \%)\end{array}$ & $\begin{array}{l}14039^{* *} \\
(2.63 \%)\end{array}$ \\
\hline Overweight and obesity (E66) & $\begin{array}{l}8314 \\
(4.74 \%)\end{array}$ & $\begin{array}{l}8290 \\
(4.66 \%)\end{array}$ & $\begin{array}{l}10913^{* *} \\
(2.07 \%)\end{array}$ & $\begin{array}{l}13526^{* *} \\
(2.53 \%)\end{array}$ \\
\hline Nicotine dependency (F17) & $\begin{array}{l}4.215 \\
(2.40 \%)\end{array}$ & $\begin{array}{l}1766 \\
(0.99 \%)\end{array}$ & $\begin{array}{l}6925^{* *} \\
(1.32 \%)\end{array}$ & $\begin{array}{l}2422^{* *} \\
(0.45 \%)\end{array}$ \\
\hline
\end{tabular}

We give group size, age and the absolute and relative frequencies of osteoporosis, use of other medications (insulin, metformin, fibrates) and comorbid conditions for males and females in the statintreated and control group, respectively.

${ }^{*} \mathrm{P}<0.01 ;{ }^{*} \mathrm{p}<0.05$

CVD, cardiovascular disease.

the ORs for females were significantly increased with respect to males $(\mathrm{p}<0.01$; see also online supplementary table S3). After stratifying the patients by their age in 10-year-intervals, we obtained similar results (osteoporosis being overrepresented in statin-treated individuals with significantly stronger effects in females than males) (see figure 1 and online supplementary table S3). In addition, figure 1 presents that in the age-class of $40-50$ years, the relationship between statin treatment and increased odds of osteoporosis is stronger than in all other age groups.

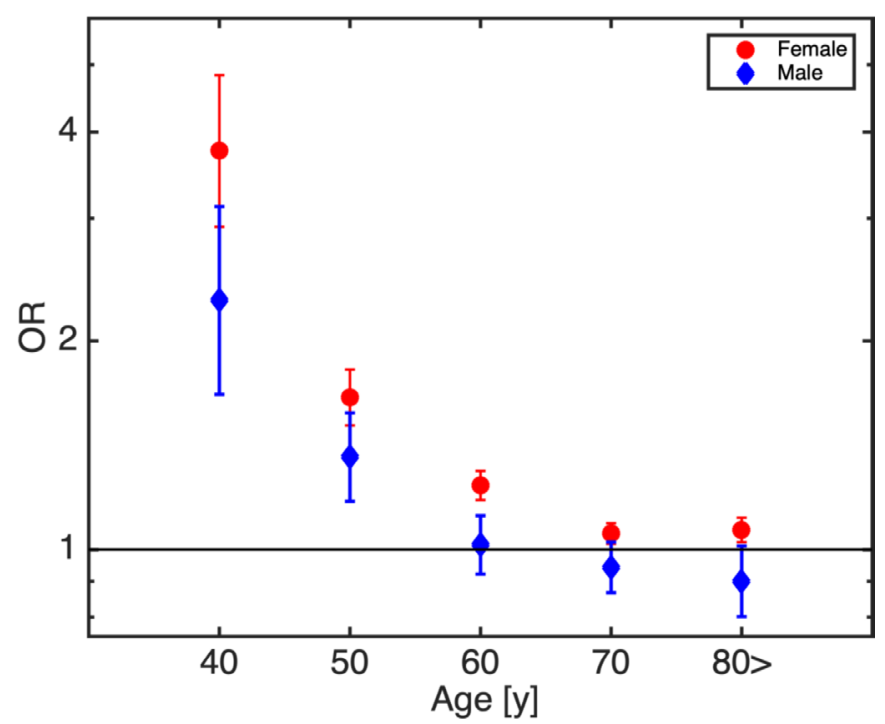

Figure 1 Age-dependent, sex-specific ORs for osteoporosis and statin use. Statin-related osteoporosis risks increase with younger age and female sex.

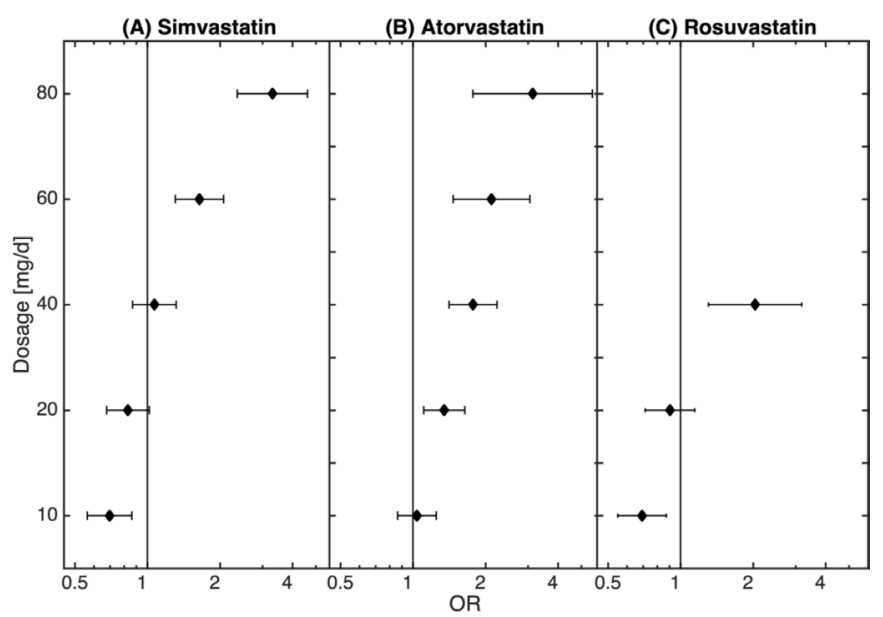

Figure 2 Dosage dependency of the statin-osteoporosis association. While low doses of statin can even be related to decreased osteoporosis risks, the disease risk clearly increases for higher doses.

\section{Comparison of the different dosages of statins in the diagnosis of osteoporosis}

There is a highly non-trivial dependence of statin dosage with the odds of osteoporosis. For low dose statin treatment $(0-10 \mathrm{mg})$ osteoporosis is underrepresented in simvastatin (OR: $0.70,95 \% \mathrm{CI} 0.56$ to $0.86, \mathrm{p}<0.01$ ), lovastatin (OR: $0.39,95 \%$ CI 0.18 to $0.84, \mathrm{p}<0.05)$, pravastatin $(\mathrm{OR}$ : $0.68,95 \% \mathrm{CI} 0.52$ to $0.89, \mathrm{p}<0.01)$ and rosuvastatin $(\mathrm{OR}$ : $0.69,95 \%$ CI 0.55 to $0.87, \mathrm{p}<0.01)$. However, the relationship between statin treatment and osteoporosis reverses with increased dosages. Particularly, this is the case for simvastatin, atorvastatin and rosuvastatin (note that for the remaining types of statin the patient numbers were too low to reliably estimate dosage -dependence) (see figure 2 and table 2). There we show that the diagnosis of osteoporosis was overrepresented in the group treated with $>40-60 \mathrm{mg}$ of simvastatin per day (OR: $1.64,95 \%$ CI 1.31 to $2.07, \mathrm{p}<0.01$ ) and further increased with the increase of the daily dosage $(>60-80 \mathrm{mg}$ simvastatin: OR: $3.30,95 \% \mathrm{CI} 2.36$ to $4.62, \mathrm{p}<0.01)$. The fact that the diagnosis of osteoporosis was overrepresented in higher dosages of statin treatment could be also observed for atorvastatin (>10-20 mg: OR: 1.35 , 95\% CI 1.11 to $1.64, \mathrm{p}<0.01$; $>20-40 \mathrm{mg}$ : OR: $1.78,95 \%$ CI 1.41 to 2.23 , $\mathrm{p}<0.01$; > 40-60 mg: OR: $2.12,95 \%$ CI 1.47 to $3.06, \mathrm{p}<0.01$; $>60-80 \mathrm{mg}$ : OR: $3.14,95 \% \mathrm{CI} 1.77$ to $5.56, \mathrm{p}<0.01)$ and for rosuvastatin (>20-40 mg: OR: $2.04,95 \% \mathrm{CI} 1.31$ to 3.18 , $\mathrm{p}<0.01$ ); the detailed description of the relationship of the dosages of statins with the diagnosis of osteoporosis with fracture is presented in online supplementary table S4. As demonstrated in online supplementary table S6, age was homogenous distributed over the different groups of statins.

To investigate whether the dosage-dependent relationship between statin use and osteoporosis risk as shown in figure 2 might be confounded by comorbidities such as arthritis, CVD, diseases of the arteries, stroke, diabetes, renal failure, nicotine dependence, overweight and obesity, and diseases possibly treated with corticosteroids such as asthma, Crohn's disease or chronic obstructive pulmonary disease, we repeated the logistic regression analysis while excluding all patients with the given comorbidity, see online supplementary files (baseline tests, including online supplementary figures S2-S7). We find that the exclusion of these patients does not change the results qualitatively. All considered regression models have adjusted 
Table 2 Individual statin dosage-dependent ORs of osteoporosis $(95 \% \mathrm{Cl})$ obtained from the logistic regression model

\begin{tabular}{|c|c|c|c|c|c|c|}
\hline All & Lovastatin & Fluvastatin & Pravastatin & Simvastatin & Atorvastatin & Rosuvastatin \\
\hline $0-10 \mathrm{mg}$ & 0.39 * & 1.00 & $0.68^{* *}$ & $0.70^{* *}$ & 1.04 & 0.69 ** \\
\hline $\mathrm{Cl}$ & 0.18 to 0.84 & 1.00 to 1.00 & 0.52 to 0.89 & 0.56 to 0.86 & 0.86 to 1.25 & 0.55 to 0.87 \\
\hline $10-20 \mathrm{mg}$ & 1.06 & $0.59 * *$ & 0.87 & 0.83 & $1.35^{* *}$ & 0.90 \\
\hline $\mathrm{Cl}$ & 0.68 to 1.64 & 0.42 to 0.82 & 0.70 to 1.07 & 0.68 to 1.02 & 1.11 to 1.64 & 0.71 to 1.15 \\
\hline $20-40 \mathrm{mg}$ & 1.59 & 0.85 & 1.01 & 1.07 & 1.78 ** & $2.04^{* *}$ \\
\hline $\mathrm{Cl}$ & 0.83 to 3.07 & 0.69 to 1.04 & 0.81 to 1.26 & 0.87 to 1.32 & 1.41 to 2.23 & 1.31 to 3.18 \\
\hline $40-60 \mathrm{mg}$ & & 0.91 & & $1.64^{* *}$ & $2.12^{* *}$ & \\
\hline $\mathrm{Cl}$ & & 0.74 to 1.11 & & 1.31 to 2.07 & 1.47 to 3.06 & \\
\hline $60-80 \mathrm{mg}$ & & 1.09 & & 3.30 ** & $3.14^{* *}$ & \\
\hline $\mathrm{Cl}$ & & 0.87 to 1.35 & & 2.36 to 4.62 & 1.77 to 5.56 & \\
\hline Adj. $R^{2}$ & 0.94 & 0.94 & 0.94 & 0.93 & 0.95 & 0.94 \\
\hline Max. VIF & 4.21 & 3.26 & 3.04 & 2.74 & 2.87 & 3.29 \\
\hline
\end{tabular}

${ }^{*} \mathrm{P}<0.01 ;{ }^{*} \mathrm{p}<0.05$.

The bold values represent the significant results.

VIF, variance inflation factor.

R-squared statistics from the range 0.71-0.96 (see table 2 and online supplementary table S5). To test for multicollinearity, we considered the VIF for each variable and found the maximum value to be 4.21, indicating that multicollinearity is not an issue in the data (see table 2 and online supplementary table S5).

\section{Sex-specific analysis}

In a sex-specific analysis, the obtained results could be confirmed with slight differences as described in detail in the online supplementary material (see online supplementary table S5 and figure S1.

\section{DISCUSSION}

The aim of the present study was to investigate the relationship of statin therapy with osteoporosis. Our results showed that osteoporosis was overrepresented in statin-treated patients in the general study population. Thus, by splitting the study cohort in the different kinds of statins and dosages, there was a dosedependent relationship with a diagnosed osteoporosis. Therefore, our results which showed that the diagnosis of osteoporosis was overrepresented in high-dose and underrepresented in lowdose statin treatment seem to be of great importance as they first show that it is important to analyse the different dosages and substances of statins.

Several studies have investigated whether HMG-CoA reductase inhibition, the main mechanism of statins, affects BMD. However, one of the main limitations of existing studies is that they did not investigate the relationship between the different kinds of statins (including potency and dosages) and the occurrence of osteoporosis in detail. A recent meta-analysis concluded that statin treatment had a tendency towards a positive effect on the reduction of fracture risk and marked improvement of BMD in statin-treated patients. ${ }^{3}$ A large meta-analysis conducted in Taiwan, including 45342 patients in the statin cohort and 115594 patients in the control cohort, stated that statin therapy correlates with a decreased risk of osteoporosis when taken daily over a longer period of time, however, also not accounting for the different types of statins and their dosages. ${ }^{7}$ In the present study, there was an increased risk of being diagnosed with osteoporosis in the general study population of statin-treated patients when compared with controls. However, the risk of being diagnosed with osteoporosis under statin-treatment decreased as a function of age, which could indicate that a longer statin treatment could be related to a lower occurrence of the diagnosis of osteoporosis. To the best of our knowledge, this is the first study which shows that it is important to consider the different kinds of substances and dosages when investigating the relationship of osteoporosis and statin therapy. Therefore, we could show that low-dose statin treatment with daily dosages lower or equal to $10 \mathrm{mg}$ of pravastatin, lovastatin, simvastatin and rosuvastatin was related to an underrepresentation of osteoporosis. Lin et al also compared different types of statins but did not investigate the effects of different daily dosages of the statins on the prevalence rate of osteoporosis. Thus, in their study, they investigated the effect of statins on the probability of developing new-onset osteoporotic fractures (NOFs) and concluded that a therapy with rosuvastatin and atorvastatin was related to a risk reduction of NOFs, significantly stronger when compared with simvastatin treatment. ${ }^{8}$ However, our results demonstrate that it is important to analyse the different kinds and dosages of statins. Rejnmark et al compared 124655 fracture cases with 373962 controls and found out that patients who had a fracture were less likely to use statins than the controls. ${ }^{19}$ In accordance with these findings, the present study also demonstrates an underrepresentation of osteoporosis in statin-treated patients, but only in patients on low dose statin therapy and not on high dose treatment of at least 1 year. Therefore, the increase of the dosage of statins was related to an overrepresentation of osteoporosis. A retrospective cohort study by Ward et al also omitted specifying the type of statin when comparing the fracture incidence of 6967 patients taking statins vs an equal number of controls. About one third of the patients received maximum dosages for simvastatin, pravastatin and atorvastatin, which were defined as $80 \mathrm{mg}$, and $40 \mathrm{mg}$ for rosuvastatin. Although statins seem to decrease the risk of femoral neck fractures, there was no difference in the overall fracture risk when compared with the controls. ${ }^{20}$ In light of numerous publications presenting rather heterogenous results while pursuing the same research question, we attempted to propose additional explanations for the observed discrepancies. Likely causes for different conclusions about whether or not statins are beneficial for bone health among various studies might be genetic determinants concerning CYP19A1/aromatase levels ${ }^{21}$ as this enzyme is responsible for the peripheral conversion of testosterone to oestrogen. It is a well-known fact that females are more commonly diagnosed with osteoporosis when compared with males, which was also the case in the present study. Furthermore, it is also known that the risk of osteoporosis, including 
a higher risk of bone fractures, is especially high in postmenopausal women. ${ }^{22}$ In the postmenopausal state, oestradiol plays a crucial role in the maintenance of $\mathrm{BMD}^{23}$ and, thus, one has to keep in mind that oestrogens are cholesterol derivates ${ }^{24}$ and play a significant role in bone metabolism by inhibiting bone resorption. ${ }^{25}$ Thus, whether higher dosages of statins could inhibit the synthesis of sex hormones, via HMG-CoA-reductase inhibition, is of special interest, as we could show that an increase in the dosages of statins was related to an exaggerated increase and overrepresentation of diagnosed osteoporosis cases in the whole study population, and additionally significantly stronger in women than when compared with men. Women, especially due to lower oestrogen levels in the post menopause, are more likely to have an insufficient BMD. ${ }^{26} 27$ In men, free testosterone levels are positively associated with higher levels of BMD and inversely related to bone turnover markers. ${ }^{28}$ The sex-specific differences in the pathogenesis of osteoporosis, a decreased activity of osteoblasts in men and an increased bone resorption due to a lack of oestrogen in women, would support the theory posed above. ${ }^{3}$ In mice models, statins have been shown to reduce plasma levels of testosterone, oestradiol and progesterone, while raising levels of follicle stimulating hormone and luteinising hormone at the same time; ${ }^{29}$ similar results have also been presented in cell lines. ${ }^{30}$ In the Rotterdam study, the effect of statins in 4166 men on sexual hormones was investigated and the authors could prove that statin treatment was related to lower serum total and non-sexual hormone-binding globulin (SHBG)-bound testosterone levels. ${ }^{31}$ Lower testosterone levels under statin therapy were also observed in other studies. ${ }^{15-17}$ Another study has shown that higher levels of SHBG are associated with a decrease in BMD. ${ }^{28}$ Taken together, these findings suggest a connection between sex hormone levels and statins in the pathogenesis of osteoporosis.

There are limitations and strengths in the present study which have to be discussed. Limitations of our study include that the data extracted from the patient contingent only show the current dosage the patients are taking. However, only patients who had a statin treatment for a minimum of 1 year were included. Another limitation is that we could not confirm the diagnosis of osteoporosis, for example, with bone densitometry data, and that we had no access to relevant treatments such as corticosteroids, hormonal replacement therapy or bisphosphonates. Additionally, one has to keep in mind that diseases such as CVD, which are commonly treated with statins, are related to other diseases and conditions such as diabetes, physical inactivity, nicotine abuse or lack of hormone treatment in the menopause, all factors directly related to osteoporosis. A strength is that the compliance of the patients could be evaluated due to the data about the prescriptions of statins per year. Another strength is that the study investigated the general Austrian population and, therefore, the number of statin-treated patients is high.

\section{CONCLUSION}

In conclusion, our data suggest that osteoporosis is overrepresented in high-dosage, but underrepresented in low-dosage statin treatment. Guidelines for cholesterol lowering therapies for prevention of cardiovascular complications advise to reduce plasma low-density lipoprotein (LDL-cholesterol) levels as low as $70 \mathrm{mg} / \mathrm{dL}$ in high risk populations. ${ }^{12}$ We propose that monitoring high-risk patients, that is, postmenopausal female patients under high-dosage statin therapy, might be useful in order to offer an individual therapy to prevent or treat osteoporosis. Thus, larger and prospective studies with a focus on dosages of statins should be conducted in order to clarify the relationship with osteoporosis.

Acknowledgements We acknowledge to Dr Gottfried Endel for helping with data assessment.

Contributors Study design: ML, CM, ST, PK and AK-W. Data analysis: ML, CM, PK. Manuscript writing: ML, CM, PK. All authors read, reviewed and approved the final manuscript.

Funding This study was funded by the WWTF (MA16-045).

Competing interests None declared.

Patient consent for publication Obtained.

Provenance and peer review Not commissioned; externally peer reviewed.

Data availability statement Data are available on reasonable request. All data relevant to the study are included in the article or uploaded as supplementary information.

Open access This is an open access article distributed in accordance with the Creative Commons Attribution Non Commercial (CC BY-NC 4.0) license, which permits others to distribute, remix, adapt, build upon this work non-commercially, and license their derivative works on different terms, provided the original work is properly cited, appropriate credit is given, any changes made indicated, and the use is non-commercial. See: http://creativecommons.org/licenses/by-nc/4.0/.

\section{ORCID iD}

Alexandra Kautzky-Willer http://orcid.org/0000-0002-3520-4105

\section{REFERENCES}

1. Stone MD, Hosking DJ. Treatment of osteoporosis: current and future. Ann Rheum Dis 1991;50:663-5.

2. Zethraeus N, Borgström F, Ström O, et al. Cost-effectiveness of the treatment and prevention of osteoporosis--a review of the literature and a reference model. Osteoporos Int 2007;18:9-23.

3. An T, Hao J, Sun S, et al. Efficacy of statins for osteoporosis: a systematic review and meta-analysis. Osteoporos Int 2017;28:47-57.

4. Chan KA, Andrade SE, Boles M, et al. Inhibitors of hydroxymethylglutaryl-coenzyme A reductase and risk of fracture among older women. Lancet 2000;355:2185-8.

5. Hippisley-Cox J, Coupland C. Unintended effects of statins in men and women in England and Wales: population based cohort study using the QResearch database. BMJ 2010:340:c2197

6. Larsson BAM, Sundh D, Mellström D, et al. Association between cortical bone microstructure and statin use in older women. J Clin Endocrinol Metab 2019:104:250-7

7. Lin T-K, Chou P, Lin C-H, et al. Long-Term effect of statins on the risk of newonset osteoporosis: a nationwide population-based cohort study. PLoS One 2018;13:e0196713.

8. Lin T-K, Liou Y-S, Lin C-H, et al. High-Potency statins but not all statins decrease the risk of new-onset osteoporotic fractures: a nationwide population-based longitudinal cohort study. Clin Epidemiol 2018;10:159-65.

9. Meier CR, Schlienger RG, Kraenzlin ME, et al. Hmg-Coa reductase inhibitors and the risk of fractures. JAMA 2000;283:3205-10.

10. van Staa TP, Wegman $S$, de Vries $F$, et al. Use of statins and risk of fractures. JAMA 2001:285:1850-5.

11. Johansen ME, Green $L A$, Sen $A$, et al. Cardiovascular risk and statin use in the United States. Ann Fam Med 2014;12:215-23.

12. Catapano AL, Graham I, De Backer G, et al. 2016 ESC/EAS guidelines for the management of Dyslipidaemias. Eur Heart J 2016;37:2999-3058.

13. Sugiyama M, Kodama T, Konishi $K$, et al. Compactin and simvastatin, but not pravastatin, induce bone morphogenetic protein-2 in human osteosarcoma cells. Biochem Biophys Res Commun 2000;271:688-92.

14. Wei W, Schwaid AG, Wang $X$, et al. Ligand activation of ERR $\alpha$ by cholesterol mediates statin and bisphosphonate effects. Cell Metab 2016;23:479-91.

15. Corona G, Boddi V, Balercia G, et al. The effect of statin therapy on testosterone levels in subjects consulting for erectile dysfunction. J Sex Med 2010;7:1547-56.

16. Schooling CM, Au Yeung SL, Freeman $G$, et al. The effect of statins on testosterone in men and women, a systematic review and meta-analysis of randomized controlled trials. BMC Med 2013;11:57.

17. Stanworth RD, Kapoor D, Channer KS, et al. Statin therapy is associated with lower total but not bioavailable or free testosterone in men with type 2 diabetes. Diabetes Care 2009:32:541-6.

18. Kautzky-Willer A, Thurner S, Klimek P. Use of statins offsets insulin-related cancer risk. J Intern Med 2017:281:206-16.

19. Rejnmark L, Vestergaard P, Mosekilde L. Statin but not non-statin lipid-lowering drugs decrease fracture risk: a nation-wide case-control study. Calcif Tissue Int 2006;79:27-36. 
20. Ward IM, Mortensen EM, Battafarano DF, et al. Association of statins and risk of fractures in a military health system: a propensity score-matched analysis. Ann Pharmacother 2014;48:1406-14.

21. Eriksson AL, Perry JRB, Coviello AD, et al. Genetic determinants of circulating estrogen levels and evidence of a causal effect of estradiol on bone density in men. J Clin Endocrinol Metab 2018;103:991-1004.

22. Lane NE, Epidemiology LNE. Epidemiology, etiology, and diagnosis of osteoporosis. Am J Obstet Gynecol 2006;194(2 Suppl):S3-11.

23. Bone HG, Greenspan SL, McKeever C, et al. Alendronate and estrogen effects in postmenopausal women with low bone mineral density. Alendronate/Estrogen Study Group. J Clin Endocrinol Metab 2000;85:720-6.

24. Jefcoate $C$. High-Flux mitochondrial cholesterol trafficking, a specialized function of the adrenal cortex. J Clin Invest 2002;110:881-90.

25. Kameda T, Mano H, Yuasa T, et al. Estrogen inhibits bone resorption by directly inducing apoptosis of the bone-resorbing osteoclasts. J Exp Med 1997; 186:489-95.
26. Cole ZA, Dennison EM, Cooper C. Osteoporosis epidemiology update. Curr Rheumatol Rep 2008;10:92-6.

27. Pinheiro MM, Reis Neto ETdos, Machado FS, et al. Risk factors for osteoporotic fractures and low bone density in pre and postmenopausal women. Rev Saude Publica 2010;44:479-85.

28. Kim H-J, Koo HS, Kim Y-S, et al. The association of testosterone, sex hormone-binding globulin, and insulin-like growth factor- 1 with bone parameters in Korean men aged 50 years or older. J Bone Miner Metab 2017:35:659-65.

29. Zhang X, Li J, Zhou X, et al. Simvastatin decreases sex hormone levels in male rats. Endocr Pract 2017;23:175-81.

30. Guldvang A, Hansen $\mathrm{CH}$, Weisser JJ, et al. Simvastatin decreases steroid production in the H295R cell line and decreases steroids and FSH in female rats. Reprod Toxicol 2015;58:174-83.

31. de Keyser CE, de Lima FV, de Jong FH, et al. Use of statins is associated with lower serum total and non-sex hormone-binding globulin-bound testosterone levels in male participants of the Rotterdam study. Eur J Endocrinol 2015;173:155-65. 